\title{
O) Anstrumento
}

\section{Índios: pensando o ensino e questionando as práticas pedagógicas}

\author{
Indians: thinking about teaching and questioning pedagogical practices
}

Indios: pensando en enseñar y cuestionar prácticas pedagógicas

\author{
Edson Hely Silva ${ }^{1}$ \\ Professor do Colégio de Aplicação da Universidade Federal de Pernambuco, Recife/PE, Brasil
}

\author{
Recebido em: $17 / 08 / 2019$ \\ Aceito em: 02/12/2019
}

\section{Resumo}

De uma forma geral, um dos maiores desafios para tratar a temática indígena no ensino é a superação de imagens românticas, exóticas e folclorizadas por visões críticas sobre os povos indígenas. As mobilizações sociopolíticas indígenas contemporâneas, a presença de índios estudando no Ensino Superior, bem como a Lei no $11.645 / 2008$, que determinou a inclusão da história e das culturas indígenas nos currículos da Educação Básica, exigem conhecimentos sobre os povos indígenas para novas reflexões e abordagens e para a produção de subsídios didáticos específicos, provocando questionamentos sobre a formação de professores e as práticas pedagógicas, possibilitando um pensamento crítico, evidenciando os protagonismos dos povos indígenas na História do Brasil e, por fim, permitindo discutir estereótipos, equívocos, preconceitos e (re)conhecer os significados que representam a sociodiversidade indígena em nosso país.

Palavras-chave: Índios. Ensino. Diversidade. Práticas pedagógicas.

\begin{abstract}
Overall, one of the biggest challenges in addressing indigenous teaching issues is overcoming romantic, exotic, and folklorized images of critical views of indigenous peoples. Contemporary indigenous sociopolitical mobilizations, the presence of Indians studying in Higher Education, as well as Law No. 11.645/2008 that determined the inclusion of indigenous history and cultures in the Basic Education curricula, require knowledge of indigenous peoples for new reflections and approaches, the production of specific didactic subsidies and provoking questions about teacher education and pedagogical practices. Enabling critical thinking highlighting the protagonisms of indigenous peoples in the History of Brazil, as well as discussing stereotypes, misconceptions, preconceptions and knowing the meanings that represent indigenous sociodiversity in our country.
\end{abstract}

Keywords: Indians. Teaching. Diversity. Pedagogical practices.

\section{Resumen}

En general, uno de los mayores desafíos para abordar la temática indígena en la enseñanza es superar las imágenes románticas, exóticas y folclóricas de las opiniones críticas sobre los pueblos indígenas. Las movilizaciones sociopolíticas indígenas contemporáneas, la presencia de indios que estudian en la educación superior, así como la Ley ${ }^{\circ} 11.645$ / 2008 que determinó la inclusión de la historia y las culturas indígenas en

\footnotetext{
${ }^{1}$ E-mail: edson.edsilva@hotmail.com
} 
los planes de estudio de la educación básica, requieren conocimiento sobre los pueblos indígenas para nuevas reflexiones y enfoques, y para la producción de subsidios didácticos específicos y preguntas provocativas sobre la formación docente y las prácticas pedagógicas. Permitir un pensamiento crítico que destaque los protagonismos de los pueblos indígenas en la Historia de Brasil, así como discutir estereotipos, conceptos erróneos, preconceptos y (re)conocer los significados que representan la sociodiversidad indígena en nuestro país.

Palabras clave: Indios. Enseñanza. Diversidad. Prácticas pedagógicas.

\section{Introdução: equívocos, desinformação e preconceitos}

Nas duas situações descritas a seguir foram evidenciados ignorância, no sentido de desconhecimento, desinformação e preconceito contra os povos indígenas. Na primeira situação, diferentes povos participavam como convidados em uma reunião para discutir o formato de um curso de especialização destinado aos professores indígenas. Estava também presente um candidato às eleições na unidade de ensino pública, professor na área das chamadas Ciências Exatas. Em um intervalo da reunião, o professor-candidato se dirigiu a um dos líderes indígenas que portava um cocar na cabeça e perguntou: "E essa fantasia aí?!". Na outra situação, em um táxi apanhado próximo à Praia de Iracema, em Fortaleza (CE), ao ser questionado sobre o porquê do nome do local, respondeu o motorista: "É uma homenagem à linda índia Iracema, que se casou com José de Alencar e era vista correndo nas areias dessa praia".

A primeira situação foi relatada por uma colega que leciona em uma das unidades do IF no interior de Pernambuco. Mas é possível que tenha ocorrido em qualquer outra região do nosso país, pois expressa desconhecimentos comuns e generalizados sobre os índios até mesmo entre nossos pares. A citada situação foi extremamente vexatória! Os indígenas presentes ficaram bastante irritados com tamanha violência, houve um mal-estar generalizado. A muito custo, a colega que coordenava a reunião conseguiu serenar os ânimos. Foram feitas as explicações devidas aos índios sobre a desinformação do colega que fizera a indagação equivocada e, ao colega, sobre a sua ignorância a respeito dos índios presentes.

A segunda situação expressa as confusões e equívocos também generalizados que refletem as fragmentações e a desinformação nos aprendizados sobre os índios em nossa trajetória escolar na Educação Básica. Uma situação que também questiona e evidencia as lacunas e a qualidade da formação de professores, os subsídios didáticos, as práticas pedagógicas e as discussões sobre a temática indígena em sala de aula nas escolas não indígenas, provocando indagações acerca de quais as imagens e os discursos sobre "os índios" que aprendemos e apreendemos, seja na formação escolar, em leituras, nas 
mídias, como a TV, nos filmes ou nas atuais mídias digitais.

\section{Índios: tão próximos, tão distantes...}

Uma adolescente indígena Pankará e um adolescente indígena Xukuru do Ororubá, de famílias que migraram há décadas para o Recife, estudavam em 2019 no Colégio de Aplicação da UFPE. Os índios Pankará habitam no sertão nos municípios de Carnaubeira da Penha e Itacuruba, enquanto os indígenas ${ }^{2}$ Xukuru do Ororubá, em Pesqueira e Poção, no Agreste pernambucano. Quais os significados da presença de estudantes indígenas na universidade? Um estudo (SILVA, 2016) apresentou questionamentos de estudantes indígenas às abordagens no Curso de Licenciatura em História e no Centro de Educação da UFPE/Campus Recife: quantos indígenas estudam nesses ambientes? Identificam-se e são identificados como índios? Sentem-se contemplados em suas expressões socioculturais nas discussões pedagógicas realizadas?

O Censo IBGE/2010 constatou parcelas consideráveis da população indígena habitando as capitais afora, em cidades de médio e pequeno porte vizinhas às aldeias/territórios indígenas. Com isso, pôs em questão uma das concepções mais arraigadas ao pensarmos os índios no Brasil: as intrínsecas relações com a floresta, o campo, o mundo rural onde está localizada a maioria das aldeias/territórios indígenas. A estimativa oficial contabilizou que cerca de $36 \%$ dos índios no país estão urbanizados, não significando necessariamente que os índios sejam moradores das cidades, mas que muitas delas avançam sobre os territórios indígenas (BRASIL, 2010).

Historicamente, os deslocamentos dos indígenas para as cidades ocorrem por migrações forçadas em razão de conflitos, perseguições e violentas expulsões de suas terras e pela busca de melhores condições de vida, tendo em vista, por exemplo, as condições ambientais (como é o caso da região Nordeste, que enfrenta períodos de longas estiagens ou secas prolongadas, provocando o êxodo para as cidades de moradores no campo).

O citado Censo qualificou a pesquisa em relação aos índios quando introduziu questões referentes ao pertencimento étnico, à língua falada e ao domicílio. Os resultados censitários caracterizaram três situações sobre os indígenas no Nordeste: a primeira correspondendo às populações habitando em terras indígenas; a segunda, aos índios vivendo nas capitais, nos grandes centros, em

\footnotetext{
2 Ao longo do texto, serão utilizados os termos "índio" ou "indígena", que, como explicitado por eles, possuem um importante significado, expressando sociodiversidades que reivindicam reconhecimento de direitos sociopolíticos. A esse respeito, ver BANIWA (2006, p. 30-31).
} 
áreas urbanas próximas às aldeias/territórios indígenas, mantendo constantes laços sociais e afetivos com estes; e a terceira, às "pessoas que se autodeclaram indígenas, mas cuja sociabilidade não está primordialmente dirigida para a aldeia, nem para a cidade" (OLIVEIRA, 2011, p. 679).

O Censo também contabilizou que, das 60.995 pessoas que se declararam ou se consideraram indígenas em Pernambuco, 13.414 habitavam "fora de terras indígenas", sendo 3.665 no Recife e na região metropolitana (BRASIL, 2010). Os números citados, além de questionarem visões corriqueiras sobre os lugares de habitação dos indígenas, evidenciaram um "incômodo" para as autoridades governamentais: como lidar e atender às reivindicações desses indígenas residentes nos ambientes urbanos? Para o poder público, uma primeira questão trata-se de atribuir uma classificação para esses indígenas: "índios na cidade", "índios urbanos" ou "índios desaldeados" (NUNES, 2010), sendo a categoria "desaldeados" considerada pejorativa e, por isso, bastante criticada pelos indígenas.

A presença dos índios no universo urbano, por um lado, denuncia a falência das políticas indigenistas oficiais em não demarcar as terras indígenas, o que em muito mitigaria os deslocamentos para as cidades; por outro lado, vem se constituindo em um desafio para os estudos e as pesquisas sobre a temática indígena, exigindo um esforço teórico na busca da compreensão sobre os indígenas que se reinventam em um novo ambiente. Favorecendo reflexões, por exemplo, no âmbito da Educação atendendo às exigências da Lei no 11.645/2008, para subsidiar políticas públicas que atendam às reivindicações indígenas e contribuindo para a superação de desinformações, estereótipos e preconceitos contra os índios.

\section{Movimentos sociais e conquistas de direitos: a Lei $n=11.645 / 2008$}

A Lei no 11.645, promulgada em março/2008 e que determinou a inclusão do ensino da História e Culturas Afro-brasileiras e Indígenas nos currículos escolares da Educação Básica pública e privada, faz parte de um conjunto de mudanças provocadas pelas mobilizações da chamada sociedade civil, os movimentos sociais. São conquistas pelo reconhecimento legal de direitos específicos e diferenciados em anos recentes, quando observamos a organização sociopolítica no Brasil. Nas últimas décadas, portanto, em diversos cenários políticos, os movimentos sociais com diferentes atores conquistaram e ocuparam espaços, reivindicando o reconhecimento e o respeito às sociodiversidades.

Todavia, faz-se necessário ter em mente que o reconhecimento dessa nova configuração das sociodiversidades no Brasil não ocorre sem muitas tensões e conflitos, a exemplo dos acalorados 
debates sobre as cotas para negros nas universidades (GOMES, 2008). Porém, durante muito tempo, no Brasil, vigorou sem restrições a chamada "lei do boi". Tratava-se da Lei № 5.465 de 03/07/1968, assim conhecida por beneficiar filhos de fazendeiros e criadores de gado, que ingressavam sem o exame de vestibular nas universidades públicas, inicialmente nos cursos de Agronomia e Veterinária. Posteriormente, a Lei passou a vigorar para todos os cursos! E só foi revogada em dezembro de 1985! Ou seja, durante muitos anos existiu, em nosso país, sem contestações, cotas para ricos nas universidades públicas, pois a chamada "lei do boi" não beneficiava filhos de trabalhadores empobrecidos no campo (SILVA, 2012a).

Entretanto, na atual conjuntura sociopolítica, em que o país se reconhece pluriétnico e são questionadas as desigualdades sociais herdadas do regime escravocrata, como forma de reparar essas desigualdades, as oportunidades de ingresso para as pessoas negras e indígenas ao ensino superior vêm sendo "facilitadas". A adoção da medida foi motivo de acirrados debates e campanhas contrárias, com a defesa da meritocracia acadêmica. Contudo, quem defende essa perspectiva não questiona as condições favoráveis em que foram construídos tais méritos, em detrimento da falta de oportunidades historicamente vivenciadas por determinados grupos sociais, especificamente negros e indígenas, ainda que outros não sejam lembrados, a exemplo dos povos ciganos em nosso país.

Foi nesse contexto de acaloradas discussões polêmicas que a implementação da Lei no 11.645/2008 veio somar aos debates sobre o reconhecimento e respeito às sociodiversidades no Brasil contemporâneo. Exigindo, portanto, um repensar sobre a história do país e sobre as discussões a respeito da chamada "formação" da sociedade brasileira e da "identidade nacional" e sobre a existência de uma suposta "cultura brasileira", "nordestina", "amazônica", "mineira", "catarinense" etc. Criando, então, uma problematização das ideias e concepções a respeito da "mestiçagem", dos lugares dos índios, negros e outras minorias que formam a maioria da chamada população brasileira (SILVA, 2012b).

Passados mais de 10 anos da promulgação da Lei no 11.645/2008, observamos, além de possibilidades, alguns desafios e impasses na sua implementação. Nesse sentido, propomos uma avaliação crítica das ações para a efetivação da citada Lei nas perspectivas das reflexões a seguir. A nossa avaliação ocorre a partir de nossas experiências de pesquisas e ensino sobre a temática indígena e enquanto docente na Educação Básica, no âmbito da formação de professores, bem como no ensino nos níveis da graduação e pós-graduação em cursos no nordeste brasileiro. 


\section{Definições importantes e necessárias}

São muito importantes e necessárias as definições sobre o que seja a Educação Indígena, a Educação Escolar Indígena e o ensino da temática indígena, pois, infelizmente, com frequência presenciamos muitas confusões não somente nas afirmações de pessoas à frente de órgãos públicos na área de Educação, como também em documentos administrativos estatais. Há inúmeras atribuições equivocadas no que se refere ao significado dos referidos termos. Tais equívocos e confusões resultam, sobretudo, de desconhecimento, desinformação, preconceitos, equívocos e generalizações comumente existentes sobre a temática indígena.

A Educação Indígena (EI) é constituída por processos educativos não formais que se criam a partir das relações socioculturais e históricas vivenciadas de geração em geração entre grupos e indivíduos indígenas (BRAND, 2012; BERGAMASHI, 2010). Nesse caso, quando nos referimos à Educação Indígena (EI), é muito importante ter em mente que quem vivencia e pratica a El são os índios, e somente os índios, cotidianamente, nas aldeias, nos territórios indígenas e em seus locais de moradia. Portanto, a Educação Indígena é bem mais ampla do que ocorre na escola. A El, pensada enquanto expressões socioculturais dos povos indígenas, tem sido objeto de estudos acadêmicos e, mais precisamente, em pesquisas no âmbito antropológico, assim como da Educação.

A Educação Escolar Indígena (EEI) é compreendida a partir dos documentos oficiais, como a LDBEN (Lei de Diretrizes e Bases da Educação Nacional, de 1996), as DCEEl (Diretrizes Curriculares para a Educação Escolar Indígena, de 1999), dentre outros, e dos estudos relacionados a esse assunto (NASCIMENTO, 2005). Trata-se de uma modalidade de ensino específica, diferenciada, bilíngue ou multilíngue, em alguns casos, e também intercultural, que se constitui como espaço de organização dos processos educativos formais implementados nas escolas indígenas. Em outras palavras, a Educação Escolar Indígena (EEI) é formada pelos processos de escolarização vivenciados pelos povos indígenas.

As escolas indígenas nas aldeias/territórios indígenas são, na maioria, destinadas ao ensino do 10 ao 5 o ano do ensino fundamental e uma ou outra para o ensino médio. Embora existam escolas indígenas em áreas urbanas, a exemplo de aldeias em bairros de Dourados (MS) e Crateús (CE), geralmente, após a conclusão do 50 ano (antiga 4a série) do ensino fundamental I, os indígenas continuam os estudos nas escolas não indígenas localizadas nas áreas urbanas das cidades. Existem vários estudos e reflexões sobre como são vivenciadas as experiências nas escolas indígenas e como os indígenas se apropriaram dessa instituição colonial e colonizadora e da educação formal, que é uma ideia ocidental, a partir dos seus pontos de vistas e projetos político-pedagógicos. Nessa perspectiva, a 
EEI tem sido objeto de estudos acadêmicos na área da educação e também na antropologia, podendo ser incluída como uma cadeira específica nos cursos de formação de professores(as), particularmente nos cursos de Pedagogia, como o estudo de uma modalidade de ensino, embora desconheçamos alguma experiência desse tipo.

Por fim, o ensino da temática indígena contém reflexões sobre os povos indígenas, atualmente atendendo às exigências da Lei no 11.645/2008, tratando do assunto nas escolas não indígenas nas áreas urbanas ou rurais. Ou seja, tratar a respeito da temática indígena no ensino significa conhecer sobre os povos indígenas: sua história, as diversidades socioculturais, as formas de ser e de viver de diferentes maneiras entre si e em relação à sociedade não indígena.

Em razão da citada Lei, indiretamente, tornou-se obrigatória a temática indígena como conteúdo de ensino na formação de professores, motivo pelo qual há a necessidade de constar no currículo das universidades e instituições de formação de professores. Também suscita a formulação de políticas de formação continuada para professores em exercício docente nas redes de ensino público estadual, municipal e privado e para os(as) demais profissionais que atuam na Educação.

O que vem ocorrendo nos cursos de licenciatura, principalmente de Pedagogia, e de formação de professores é que erroneamente vem sendo incluída uma cadeira nomeada Educação Indígena quando, ao se buscar atender às exigências da Lei no 11.645/2008 para formação do professorado, o correto seria uma cadeira sobre o ensino da temática indígena.

\section{O racismo institucional}

Outro aspecto que consiste em um impasse e um desafio significativo para a efetivação da Lei no 11.645/2008 é o racismo institucional. Essa expressão do racismo foi assim definida: “O racismo institucional ou sistêmico opera de forma a induzir, manter e condicionar a organização e a ação do Estado, suas instituições e políticas públicas - atuando também nas instituições privadas, produzindo e reproduzindo a hierarquia racial” (WERNECK, 2013, p. 17).

Ocorre, na maioria das vezes, de forma sutil, nos corredores ou gabinetes das secretarias estaduais ou municipais de Educação, nos setores administrativos das escolas e também nas salas de aulas, e pode ser desde o desconhecimento sobre a referida Lei ao descrédito com as inciativas que venham a atender às suas exigências, a falta de apoio ou mesmo no impedimento, melhor dizendo, no engavetamento de processos e ações que favoreçam as discussões sobre a temática indígena. 
O racismo institucional vem sendo manifestado em ações de agentes que atuam na Educação em diferentes níveis e muitas vezes está intimamente ligado a convicções ideológicas, a concepções excludentes, racistas e ocorre quase sempre como um descompromisso intencional, porém de forma sutil, silenciosa, e, portanto, às vezes, torna-se difícil ser identificado e combatido. Esse tipo de racismo é comumente expresso nas regiões mais antigas de colonização ou onde ocorrem conflitos latentes provocados pelas invasões das terras indígenas. A exemplo do Nordeste, onde existem os chamados "índios misturados", é facilmente constatável que, no âmbito da Educação, a identidade indígena, quando não é veementemente negada ou sempre questionada, torna-se motivo de chacota, tendo sempre como horizonte comparativo o fenótipo de indígenas habitantes na região amazônica ou no Xingu, portadores de uma suposta cultura pura e imutável e que, por isso, são vistos como "índios verdadeiros", em oposição aos "índios aculturados".

\section{Controvérsia nas interpretações da legislação}

Vem ocorrendo também uma controvérsia nas interpretações da legislação recente que determinou o ensino da temática étnico-racial na Educação Básica. Por contabilizarem mais da metade da população brasileira, concentrando um considerável contingente nas áreas urbanizadas dos municípios, portanto, com maior visibilidade, os negros ocupam os espaços sociopolíticos por meio dos movimentos organizados reivindicatórios de direitos sociais. Nesse sentido, a Lei no 10.639/2003, que tornou obrigatório o ensino da História e Cultura Afro-Brasileira, foi uma conquista bastante exaltada pelo Movimento Negro, que constantemente enfatiza o seu significado para afirmação identitária e superação da discriminação racial.

Cinco anos depois, em 2008, o Governo Federal promulgou a Lei no 11.645/2008, que "estabelece as diretrizes e bases da educação nacional, para incluir no currículo oficial da rede de ensino a obrigatoriedade da temática “História e Cultura Afro-Brasileira e Indígena'”. A partir da leitura desse texto da Lei, surgiu uma controvérsia, um impasse nas interpretações: essa Lei incorporou a 10.639/2003 ou é outra lei? Ou seja, são duas leis diferentes? Se forem duas, porque o texto da Lei no 11.645/2008 afirma "História e Cultura Afro-Brasileira e Indígena"? Lembrando que no preâmbulo está escrito que a Lei de 2008 alterou a Lei no 9.394 de 20 de dezembro de 1996, e ambas estão vinculadas à LDBEN, conhecida como LDB, que em seus artigos 26-A e 79-B previa a inclusão da temática étnico-racial no ensino. Em outras palavras, as leis no 10.639/2003 e nำ11.645/2008 representam, para os movimentos 
sociais e para as organizações negras e indígenas, bandeiras de mobilizações históricas, todavia, juridicamente, a LDBEN é a legislação que rege a Educação Brasileira.

Observamos também que foram publicadas pelo MEC, em 2006, as Orientações e Ações para a Educação das Relações Étnico-Raciais, como subsídio para implementação da Lei no 10.639/2003, sendo atribuída essa conquista às mobilizações do Movimento Negro, com consideráveis aportes de recursos para publicações, para formação do professorado e para projetos que discutam ou executem ações para superação da discriminação étnico-racial, em que, de forma majoritária, o "étnico-racial" objetivamente tem contemplado apenas a temática negra.

\section{O ensino da temática indígena e as instituições formadoras de professores}

Nas universidades e nos centros de ensino, multiplicaram-se os cursos, as cadeiras, os seminários, os congressos etc. sobre a temática afro. Foram formados os NEAB (Núcleo de Estudos Afro-Brasileiro) e alguns poucos lugares um NEABI, a exemplo da Universidade Católica (UNICAP - Recife), da UFPB em seus campi e ainda da Universidade Estadual da Paraíba (UEPB), onde a letra "I" significa a inclusão dos estudos sobre a temática indígena. E, por esse e outros motivos, a Lei no 11.645/2008 é quase despercebida ou até mesmo ignorada nas discussões sobre a Educação Básica e nos estabelecimentos de ensino, permanecendo, no geral, as visões equivocadas sobre os indígenas. Tornam-se recorrentes algumas práticas "pedagógicas" que remetem a imagens de índios genéricos, desconsiderando as sociodiversidades dos povos indígenas existentes no Brasil.

Em 18/04/2016, o Diário Oficial da União publicou como Despacho do Ministro da Educação o Parecer no 14/2015. Apresentado pela Conselheira e Relatora indígena Potiguara (CE) Rita Gomes do Nascimento, o Parecer fora aprovado pelo Conselho Nacional de Educação (CNE) em 11/11/2015. Na introdução do citado Parecer, lemos que mesmo resultou de várias provocações ao CNE sobre a efetivação da Lei no 11.645/2008:

Cabe assinalar, ainda, a participação do CNE nos diversos fóruns de educação nos quais foi convidado para debater e apresentar proposições sobre o tratamento da temática no âmbito da Educação Básica e da Educação Superior, ao longo desses sete anos de existência da Lei $n$ o 11.645/2008. Finalmente, merece destaque o interesse de diferentes atores sociais, tais como professores, gestores educacionais e operadores do direito que, por meio de consultas e outras iniciativas, têm provocado o CNE a se manifestar sobre a matéria. Nesse sentido, o presente Parecer dá encaminhamento aos resultados dos estudos já realizados até então, com a intenção de responder a essas constantes solicitações (BRASIL, 2016, p. 1-2). 
Observando em linhas gerais, o Parecer, em seu texto, discorreu sobre a temática da história e da cultura dos povos indígenas na Educação Básica e o contexto legal na promoção de políticas públicas, evidenciando ações realizadas pelo MEC e por algumas instituições de Educação Superior para implementação da Lei no 11.645/2008, embora persistindo a reprodução de estereótipos, desinformação e preconceitos sobre os povos indígenas. Por essa razão, concluiu que:

Os Conselhos de Educação de todas as instâncias do sistema nacional de educação, para tanto, devem orientar, por meio de seus atos normativos, os diferentes órgãos executivos do respectivo sistema de ensino e instituições formadoras de professores e seus estabelecimentos de ensino para o esforço de organizar e reorganizar de seus projetos, programas, propostas curriculares e pedagógicas, de modo a se adequarem ao proposto na LDB, na redação dada pela Lei no 11.645/2008, acompanhando sua implementação e articulando ações e instrumentos que permitam o correto tratamento da temática da história e da cultura dos povos indígenas pelos sistemas e estabelecimentos de ensino, bem como promovendo ampla divulgação deste Parecer em atividades periódicas, com a participação das redes das escolas públicas e privadas, em termos de exposição, avaliação e divulgação dos êxitos e dificuldades do ensino e da aprendizagem da temática da história e da cultura dos povos indígenas (BRASIL, 2016, p.10 - grifos nossos).

O pouco divulgado e conhecido Parecer do CNE no 14/2015 sobre o ensino da temática indígena, em suas conclusões, enfatizou a importância do papel das "instituições formadoras de professores e seus estabelecimentos de ensino" para efetivação da Lei no 11.645/2008, contribuindo para superação de preconceitos e o (re)conhecimento das sociodiversidades indígenas existentes no Brasil.

\section{De qual "índio" estamos falando?!}

Um dos maiores desafios, de uma forma geral, para tratar da temática indígena no ensino é a superação de imagens exóticas, folclorizadas, para um (re)conhecimento das situações vivenciadas pelos povos indígenas. A escola é uma das instituições responsáveis pela veiculação de muitas ideias, imagens e informações equivocadas a respeito dos índios no Brasil. Ainda é comum, na maioria das escolas, principalmente no universo da Educação Infantil, que todos os anos, no dia 19 de abril, quando se comemora o Dia do Índio, repitam-se as mesmas práticas: enfeitam as crianças, pintam seus rostos e confeccionam penas de cartolina para colocá-las nas suas cabeças.

As crianças nas escolas são vestidas com saiotes de papel (geralmente verdes) e não faltam os gritos e cenários com ocas e florestas! Dizem que estão imitando os índios, buscando homenageá-los! Entretanto, tais supostas homenagens se referem à qual índio? As supostas imitações correspondem às 
situações atuais dos povos indígenas no Brasil? Como essas imagens ficarão gravadas na memória dos(as) estudantes desde tão cedo? Quais serão suas atitudes quando se depararem com os índios reais? Quais as consequências da reprodução dessas desinformações para o (re)conhecimento das diversidades étnicas indígenas existentes no nosso país?

O que muitas vezes aprendemos sobre os índios na escola está associado basicamente às imagens do que é também, na maioria dos casos, veiculado pela mídia: um índio genérico, ou seja, sem estar vinculado a um povo indígena concreto. Ou ainda com um biótipo de indivíduos habitantes na região amazônica e no Xingu. Com cabelos lisos, muitas pinturas corporais e adereços de penas, nus, moradores das florestas, portadores de culturas exóticas etc. Também os diversos grupos étnicos são chamados de "tribos" e assim pensados como primitivos, atrasados. Ou ainda vemos aqueles índios imortalizados pela literatura romântica do Século XIX, como nos livros de José de Alencar, onde são apresentados índios belos e ingênuos, ou valentes guerreiros, ameaçadores canibais, ou seja, bárbaros, bons selvagens ou heróis.

As imagens e os discursos que afirmam os indígenas na Amazônia como "puros", autênticos e "verdadeiros" em oposição aos habitantes de outras regiões do país, principalmente nas regiões mais antigas da colonização portuguesa, a exemplo do Nordeste, baseiam-se em uma ideia equivocada de culturas melhores, superiores ou inferiores, sendo que as pesquisas antropológicas evidenciam as culturas como dinâmicas, apenas diferentes e, mais do que isso, como resultado das relações históricas entre os diferentes grupos humanos. Ou seja, para melhor se compreender os atuais povos indígenas nas suas sociodiversidades, faz-se necessário perceber as diversas experiências vivenciadas por esses povos nos diversos processos de colonização, que resultaram na história das relações socioculturais ao longo de mais de 500 anos no Brasil, buscando compreender as expressões socioculturais indígenas como produto das relações históricas em cada região do país.

Se, por um lado, em razão da ignorância e do desconhecimento, tais discursos e imagens equivocadas sobre uma suposta "pureza" dos grupos indígenas existem até mesmo na Amazônia, por outro, mesmo naquela região são utilizados "preconceitos" e discursos perversos para negar as identidades indígenas. Como exemplo, temos os argumentos usados pelos grandes latifundiários, madeireiras, empresas de mineração privadas e até públicas, grandes projetos governamentais para construções de barragens e hidrelétricas e demais interessados nas terras dos povos indígenas. Portanto, negar as identidades dos povos indígenas é a condição para omitir seus direitos, principalmente aos seus territórios. 
O citado Censo IBGE/2010 apontou a existência de 305 povos indígenas no Brasil, falantes de 274 línguas, e contabilizou cerca de 900 mil indivíduos (INSTITUTO, 2010), significando que tratar sobre os grupos que se convencionou chamar-se genericamente de "índios" é uma situação parecida a olhar um caleidoscópio: são povos em suas múltiplas expressões socioculturais, diversos entre si e diferentes de nossa sociedade. Pensar os povos indígenas é, portanto, pensar sempre em experiências sócio-históricas plurais e diferenciadas.

O pouco conhecimento generalizado sobre os povos indígenas está associado basicamente à imagem do índio que é tradicionalmente veiculada pela mídia: um índio genérico, vivendo nas chamadas "tribos", visão da perspectiva eurocêntrica, etnocêntrica e evolucionista de uma suposta hierarquia de raças na qual os índios ocupariam obviamente o último degrau da chamada "civilização".

Portanto, além de ser necessário descontruir a ideia de uma suposta identidade genérica nacional ou regional, é necessário também questionar as afirmações que expressam uma cultura hegemônica que nega, ignora e mascara as diferenças socioculturais, questionando ainda supostas identidade e cultura nacionais que constituem o discurso impositivo de um único "povo brasileiro". Uma unidade anunciada muitas vezes em torno da ideia de raça, um tipo biológico a exemplo das imagens sobre o mulato, o mestiço, o nordestino, o sertanejo, o pernambucano, dentre outras.

São ideias e narrativas que fundamentam as supostas identidade e cultura nacionais, que, como mencionadas acima, omitem as diferenças de classes sociais, gênero, étnico-raciais etc. ao buscar uniformizá-las, mascarando também os processos históricos marcados pelas violências de grupos politicamente hegemônicos (HALL, 1999), negando ainda as violências sobre grupos, a exemplo dos povos indígenas e os oriundos da África que foram submetidos a viver em ambientes coloniais. Observemos ainda que as identidades nacionais, além de serem fortemente marcadas pelo etnocentrismo, são também marcadas pelo sexismo: diz-se o mulato, o mestiço, o catarinense, o paranaense, o gaúcho etc., acentuando-se o gênero masculino.

É necessário, então, problematizar ainda as ideias e afirmações de identidades generalizantes como a mestiçagem no Brasil, sendo um discurso para negar, desprezar e suprimir as sociodiversidades existentes no país. Afirmar os direitos e as diferenças é, pois, questionar o discurso da mestiçagem como identidade nacional, usado para esconder a história de índios e negros na História do Brasil. Portanto, o (re)conhecimento das sociodiversidades indígenas se constitui em um grande desafio para o ensino da 
temática indígena.

\section{A formação para o ensino da temática indígena}

A formação para o professorado e os agentes que atuam na educação no âmbito das relações étnico-raciais sobre a temática indígena talvez seja o maior desafio a ser enfrentado. A formação específica tem que ser pensada em duas frentes: nos cursos de licenciatura e de formação para o magistério e para aqueles professores em exercício e demais profissionais que atuam na educação.

Com o desconhecimento do Parecer 14/2015 do CNE, contendo orientações para a implementação da Lei no 11.645/2008, há notícia de pouquíssimas iniciativas em centros de formação de professores que incluíram cadeiras específicas sobre a temática indígena. Essa inclusão se faz necessária não somente nos cursos de Pedagogia, mas também nos cursos de licenciatura em todas e diversas áreas do conhecimento, a exemplo da Matemática, Química, Física, Botânica etc.

Existe uma demanda implícita suscitada pela Lei que, todavia, esbarra em pelo menos duas situações-limite: o desconhecimento da normatização complementar acima citada, e, sobretudo, a carência de profissionais especializados para atender à demanda instaurada, seja nos espaços educacionais públicos ou privados. As universidades, enquanto centros de formação, não priorizaram a formação de profissionais sobre a temática indígena, isso porque o assunto foi sempre considerado residual e, por conseguinte, de menor relevância, ignorado até na maioria dos cursos de Ciências Humanas e Sociais.

Observa-se, por exemplo, na área da História: quando ocorrem concursos públicos no ensino superior para a cadeira História Indígena, em geral, os editais flexibilizam as exigências para candidatos que possuam formação em Antropologia, em razão da carência de especialistas sobre a temática indígena na própria área da História. Situações semelhantes também ocorrem se os concursos forem na área de educação e destinados ao ensino nos cursos de licenciaturas.

A outra situação diz respeito à formação daquele professor que se encontra em exercício docente na educação básica, as conhecidas lacunas na formação de professores, cuja responsabilidade é das secretarias municipais e estaduais de Educação. Nos últimos tempos, em várias cidades, o Ministério Público tem exigido desses órgãos ações para implementação da Lei no 11.645/2008. Ocorre que as citadas secretarias, ao procurar atender às exigências em geral, têm improvisado formações realizadas em curtíssimos espaços de tempo, às vezes durante uma manhã ou uma tarde, de forma massiva, 
reunindo o professorado e os profissionais da educação de todos os níveis e modalidades de ensino em grandes auditórios. E ainda recorrendo a supostos formadores "especialistas", nem sempre reconhecidos como tais nos estudos/pesquisas sobre a temática que afirmaram abordar. Nesses casos, ao Ministério Público falta acompanhar e fiscalizar bem de perto todo o processo para o cumprimento do que determinou a Lei sobre a temática indígena.

É recomendável, sempre que possível, a participação efetiva de indígenas nesses cursos de formação, pois suas experiências de vida, narrativas e expressões socioculturais contribuem para desmistificações e para um maior conhecimento sobre os povos indígenas. Também são recomendáveis visitas pedagógicas de professores, profissionais da educação e estudantes a aldeias/territórios indígenas e também de indígenas às escolas. Esses intercâmbios, quando prévia e devidamente preparados, são oportunidades ímpares de aprendizados sobre os povos indígenas. E, se realizados nas aldeias/territórios indígenas localizados próximo às escolas, além de favorecer a superação de preconceitos tão comuns nessas regiões, contribuem para a solidariedade com as mobilizações indígenas pelas reivindicações de seus direitos sociais.

No âmbito da chamada formação continuada de professores, outro aspecto ainda mais desafiador vem sendo a superação de um limite: a ausência do compromisso com o ensino sobre a temática indígena. O desafio é como motivar o professor, o profissional da educação que atua há vários anos, seja em sala de aula, seja em outras atividades pedagógicas, para o interesse pelo aprendizado. A falta de conhecimento a respeito dos povos indígenas, seja por convicções ideológicas, seja por posturas racistas e excludentes, bem como as precárias condições de trabalho, não estimulam as ações docentes sobre o ensino da temática indígena.

\section{Os subsídios didáticos}

Os poucos subsídios didáticos, sejam publicações específicas, documentários, filmes, sites etc. disponíveis sobre a temática indígena em geral são produções locais e de circulação/divulgação bastante restritas. Em comparação à considerável quantidade sobre a temática afro-brasileira, os subsídios elaborados pelo MEC a respeito dos povos indígenas, embora enviados a todas as escolas no país, ainda são uma produção mínima. A quantidade de subsídios, reconhecidamente tão pequena, talvez se justifique pela complexidade e necessidade de especialistas que discutam o tema, pelos custos exigidos para a produção ou mesmo ainda pela pouca importância e prioridade dedicada ao assunto. A situação 
significa uma lacuna considerável para o ensino e, com isso, perpetuam-se imagens e discursos equivocados sobre o "índio" na maioria dos livros didáticos, geralmente a única e mais usada fonte de informações sobre os povos indígenas.

Embora a Lei no 11.645/2008, em seu artigo 2ํ, afirme que “Os conteúdos referentes à história e cultura afro-brasileira e dos povos indígenas brasileiros serão ministrados no âmbito de todo o currículo escolar, em especial nas áreas de educação artística e de literatura e história brasileiras", a temática indígena, seguindo o que prevê a base curricular nacional comum, é tratada pontualmente no 6ำ ano do Ensino Fundamental de História e no 1으 Ano do Ensino Médio. Embora no 6을 Ano, lamentavelmente, os povos indígenas sejam citados nos livros didáticos quando se discute as origens da humanidade na condição de "povos primitivos".

No que diz respeito às outras áreas do conhecimento, mesmo em Educação Artística e Literatura, são tímidas as iniciativas que abordam pontualmente a temática indígena e, em geral, como sempre ocorreu, de forma folclorizada, baseada em pesquisas superficiais e evidenciando-se o exotismo cultural de um índio genérico, o que contribui para a continuidade das desinformações sobre a situação em que vivem os povos indígenas no Brasil.

Outra questão séria é a falta de subsídios específicos sobre a temática indígena em acervos nos centros de ensino e ainda mais nas bibliotecas das escolas de educação básica, o que torna difícil ou, em algumas situações, até impossível o acesso às informações sobre os povos indígenas. Esta é uma situação que também pode ser constatada nas bibliotecas das universidades e centros de formação de professores onde existem diversos cursos de licenciatura.

São bastante conhecidas a política de adoção do livro didático nas escolas públicas, as formas de escolha, os interesses editoriais e mercadológicos e as margens possíveis de participação no processo do professorado e demais profissionais que atuam na educação. O livro didático constitui um dos instrumentos, senão o subsídio mais comum utilizado em sala de aula. É um guia com conteúdo a ser estudado por professores e alunos, todavia, trata-se de um subsídio que expressa valores, concepções e visões de mundo. Nesse sentido, "várias pesquisas demonstraram como textos e ilustrações de obras didáticas transmitem estereótipos e valores dos grupos dominantes, generalizando temas como família, criança, etnia, de acordo com os preceitos da sociedade burguesa" (BITTENCOURT, 2002, p. 72).

Um estudo sobre os livros didáticos de História publicados entre os anos de 1999 e 2005, destinados às séries 5a a $8^{a}$ do ensino fundamental (atuais 60 ao 90 ano), que foram distribuídos às escolas públicas e avaliados pelo Programa Nacional do Livro Didático (PNLD-MEC), concluiu que os 
índios eram caracterizados como "primitivos", reproduzindo pressupostos evolucionistas e valores etnocêntricos. Os povos indígenas foram citados como "tribos" vivendo na "Pré-história", considerados em processo de extinção e tendo suas expressões socioculturais e religiosas tratadas de formas pejorativas. Além das inúmeras imprecisões classificatórias e conceituais nas abordagens sobre as diversidades sociolinguísticas, a negação da presença indígena ao longo da História do Brasil foi constatada como uma ausência de fundamentação teórica nos conteúdos (GOBBI, 2010).

Afora uma extrema carência de subsídios didáticos sobre a temática indígena para a educação infantil, constatamos que, mesmo após a promulgação da Lei no 11.645/2008, os manuais didáticos de História ainda que aprovados/recomendados pelo PNLD, salvo algumas poucas exceções, continuam trazendo nos conteúdos sobre os povos indígenas os mesmos equívocos das abordagens anteriores (MACÊDO, 2009). O mais preocupante é que se trata de livros amplamente destinados às escolas públicas de todo o país, utilizados para informação/formação de uma geração de estudantes, professorado e profissionais da educação.

Nesse sentido, uma pesquisadora afirmou:

Dar às crianças e adolescentes a oportunidade de aprender sobre os povos indígenas é dar-Ihes a oportunidade de conhecer a grande riqueza que reside na diversidade cultural existente no Brasil, riqueza que deve ser valorizada e respeitada. Como fontes de aprendizado que são e pelo lugar que ocupam no sistema educacional brasileiro, os livros didáticos deveriam abordar a temática indígena e a diversidade cultural de modo que os alunos percebessem tal valor (GOBBI, 2012, p. 242).

É importante acrescentar que também se trata de uma oportunidade para o professorado e os demais profissionais que atuam na educação, tendo presentes as estimativas do Censo IBGE/2010, que contabilizou cerca de $40 \%$ da população indígena habitando em áreas urbanizadas e, ainda, que o universo escolar se trata de um ambiente onde, sobremaneira, é possível a formação crítica para se (re)conhecer e vivenciar as sociodiversidades étnico-raciais.

\section{Considerações finais}

A Lei no 11.645/2008 foi uma conquista dos movimentos sociais e simboliza as transformações históricas recentes que ocorreram nos últimos anos no Brasil. Procuramos, a partir da constatação de algumas possibilidades, desafios e impasses, realizar breve balanço crítico a respeito da implementação da Lei. Mas buscamos fazer uma avaliação que não seja tão somente pessimista, pois, embora com os 
equívocos apontados, as poucas iniciativas de algumas universidades e centros de ensino, principalmente nos cursos de Pedagogia, que têm incluído disciplinas de Educação Indígena (e até mesmo com nomes atípicos como "Culturas nativas") ou disciplinas para o ensino sobre as relações étnico-raciais (onde se prioriza a temática afro e bem menos a indígena), são contabilizados pequenos avanços.

Portanto, ocorreram tímidos avanços a serem considerados. Em razão da Lei no 11.545/2008, recursos foram destinados para publicações, embora com pouca circulação, sobre a temática indígena nos governos anteriores pelo MEC por meio da extinta SECADI (Secretaria de Educação Continuada, Alfabetização, Diversidade e Inclusão). A exemplo do livro $O$ ensino da temática indígena: subsídios didáticos para o estudo das sociodiversidades indígenas (ANDRADE; SILVA, 2017), disponível em formato digital, que resultou de um curso de especialização para professores na educação básica, promovido em 2016 na UFRPE/Campus Recife, também subsidiado pela SECADI.

Também ocorreram iniciativas, ainda que de formas equivocadas, de formações destinadas ao professorado e aos profissionais da educação sobre a temática indígena. Por isso é que se faz urgente e necessária a divulgação para conhecimento amplo de quem atua na educação do Parecer do CNE 14/20015 com as orientações sobre o ensino da temática indígena, no sentido de estabelecer definições, sugestões e indicações de como tratar o assunto no ensino, conforme a determinação legal na educação básica, e também no ensino superior, mais especificamente nas licenciaturas e nos cursos para formação de professores.

O estudo da temática indígena, a exemplo do citado curso acima e dos conteúdos das aulas publicados em forma de capítulos no também referido livro, além de questionar visões colonizadoras, ufanismos e concepções deterministas sobre o lugar e os protagonismos sociopolíticos dos povos indígenas na História do Brasil, superando ideias românticas, exóticas e folclóricas sobre os índios, possibilita repensar a História e discutir estereótipos, equívocos, preconceitos e (re)conhecer os significados da riqueza que representam as sociodiversidades indígenas em nosso país.

\section{Referências}

ANDRADE, Juliana Alves de; SILVA, Tarcísio Augusto Alves da (Orgs.). O ensino da temática indígena: subsídios didáticos para o estudo das sociodiversidades indígenas. Recife: Edições Rascunhos, 2017.

BANIWA, Gersem dos Santos Luciano. O índio brasileiro: o que você precisa saber sobre os povos indígenas no Brasil de hoje. Brasília: MEC/Secad: Museu Nacional/UFRJ, 2006. p.30-31. 
BERGAMASCHI, Maria Aparecida. Povos indígenas e o ensino de História: a Lei no 11.645/2008 como caminho para a interculturalidade. In: BARROSO, Vera Lúcia Maciel; BERGAMASCHI, Maria Aparecida; PEREIRA, Nilton Mullet; GEDOZ, Sirlei Teresinha; PADRÓS, Enrique Serra. (Orgs.). Ensino de História: desafios contemporâneos. Porto Alegre: EST/Exclamações/ANPUH/RS, 2010. p.151-166.

BITTENCOURT, Circe Maria Fernandes (Org.). O saber histórico na sala de aula. 6. ed. São Paulo: Contexto, 2002.

BRAND, Antônio. Saberes tradicionais e as possibilidades de seu trânsito para os espaços escolares. In: REUNIÃO DA ANPED, 35, Porto de Galinhas, 2012. Anais eletrônicos do GT 21 - Educação e relações étnico-raciais. Disponível em: http://www.anped.org.br/grupos-de-trabalho/gt21educa\%C3\%A7\%C3\%A3o-e-rela\%C3\%A7\%C3\%B5es-\%C3\%A9tnico-raciais. Acesso em: 20 out. 2019.

BRASIL. Diretrizes Operacionais para a implementação da história e das culturas dos povos indígenas na Educação Básica, em decorrência da Lei no 11.645/2008. Parecer CNE/CEB no 14/2015, Diário Oficial da União. Seção 1, Brasília/DF, p. 43, 18 abr. 2016,

BRASIL. Lei n. 10.639, de 9 de janeiro de 2003. Altera a lei n. 9.394, de 20 de dezembro de 1996, que estabelece as diretrizes e bases da educação nacional, para incluir no currículo oficial da Rede de Ensino a obrigatoriedade da temática "História e Cultura Afro--Brasileira", e dá outras providências. Diário Oficial da União: Brasília, DF, 10 jan. 2003.

BRASIL. Lei n. 11.645/2008, de 10 de março de 2008. Altera a lei n. 9.394, de 20 de dezembro de 1996, modificada pela lei n. 10.639, de 9 de janeiro de 2003, que estabelece as diretrizes e bases da educação nacional, para incluir no currículo oficial da rede de ensino a obrigatoriedade da temática "História e Cultura Afro-Brasileira e Indígena". Diário Oficial da União: Brasília, DF, 11 mar. 2008.

GOBBI, Izabel. O que os livros didáticos dizem sobre os povos indígenas. In: TASSINARI, Antonella Maria Imperatriz; GRANDO, Beleni Saléte; ALBUQUERQUE, Marcos Alexandre dos Santos. (Orgs.). Educação indígena: reflexões sobre noções nativas de infância, aprendizagem e escolarização. Florianópolis: Editora da UFSC, 2012. p. 223-244.

GOBBI, Izabel. Desafios do ensino sobre indígenas nas escolas: uma reflexão a partir dos livros didáticos de História. In: Cadernos do LEME, Campina Grande, v. 2, n. 2, jul./dez. 2010, p. 41 - 57.

GOMES, Nilma Lino. A questão racial na escola: desafios colocados pela implementação da Lei 10.639/2003. In: MOREIRA, Antonio Flavio Barbosa; CANDAU, Vera Maria. Multiculturalismo: diferenças culturais e práticas pedagógicas. 2. ed. Petrópolis: Vozes, 2008. p.67-89.

HALL, S. A identidade cultural na pós-modernidade. 3. ed. Rio de Janeiro: DP\&A, 1999.

INSTITUTO BRASILEIRO DE GEOGRAFIA E ESTATístICA. Censo 2010. Disponível em: http://censo2010.ibge.gov.br/resultados. Acesso em: 28 fev. 2017.

MACÊDO, Celênia de Souto. 0 índio como o outro: o desafio de construir uma identidade positiva a partir dos livros didáticos. 149 f. Dissertação (Mestrado em Ciências Sociais) - Programa de Pós- 
Graduação em Ciências Sociais, Universidade Federal de Campina Grande, Campina Grande/PB, UFCG, 2009.

NASCIMENTO, Rita Gomes do. Educação escolar indígena: um olhar sobre a formação diferenciada no Ceará. In: Anais digitais do GT 25 - Educação Indígena, XVII EPENN, Belém/PA, 2005.

NUNES, Eduardo Soares. Aldeias urbanas ou cidades indígenas? Reflexões sobre índios e cidades. In: Espaço Ameríndio, Porto Alegre, v. 4, n. 1, p. 9-30, jan./jun. 2010.

OLIVEIRA, João Pacheco de. Trama histórica e mobilizações indígenas atuais: uma antropologia dos registros numéricos no Nordeste. In: OLIVEIRA, João Pacheco de. (Org.). A presença indígena no Nordeste: processos de territorialização, modos de reconhecimento e regimes de memória. Rio de Janeiro: Contra Capa, 2011. p. 653-687.

SILVA, Maria da Penha da. O olhar dos/as cursistas indígenas sobre o curso de História da UFPE: discutindo conteúdos e abordagens históricas sobre os povos indígenas. $73 \mathrm{f}$. Trabalho de conclusão de curso (Especialização em Culturas e História dos Povos Indígenas no Brasil) - Pós-Graduação em Educação, Universidade Federal Rural de Pernambuco, Recife, 2016.

SILVA, Edson. História e diversidades: os direitos às diferenças. Questionando Chico Buarque, Tom Zé, Lenine... In: MOREIRA, Harley Abrantes. (Org.). Africanidades: repensando identidades, discursos e o ensino de História da África. Recife: UPE/Livro Rápido, 2012a. p. 11-37.

SILVA, Edson. Os povos indígenas e o ensino: reconhecendo as sociodiversidades nos currículos com a Lei 11.645. In: ROSA, Adriana; BARROS, Natália (Orgs.). Ensino e pesquisa na educação básica: abordagens teóricas e metodológicas. Recife: EDUFPE, 2012b. p. 75-87.

WERNECK, Jurema. Racismo institucional: uma abordagem conceitual. São Paulo: GELEDÉS, 2013. 